Central Washington University

ScholarWorks@CWU

All Faculty Scholarship for the College of the Sciences

$9-28-2002$

\title{
Whole mantle shear structure beneath the East Pacific Rise
}

Timothy I. Melbourne

Donald V. Helmberger

Follow this and additional works at: https://digitalcommons.cwu.edu/cotsfac

Part of the Geology Commons, Geophysics and Seismology Commons, and the Tectonics and Structure Commons 


\title{
Whole mantle shear structure beneath the East Pacific Rise
}

\author{
Timothy I. Melbourne \\ Department of Geological Sciences, Central Washington University, Ellensburg, Washington, USA
}

Donald V. Helmberger

Seismological Laboratory, California Institute of Technology, Pasadena, California, USA

Received 31 January 2000; revised 25 November 2001; accepted 30 November 2001; published 28 September 2002.

[1] We model broadband seismograms containing triplicated $S, S^{2}$, and $S^{3}$ along with $S c S$ to produce a pure path one-dimensional model extending from the crust to the core-mantle boundary beneath the East Pacific Rise. We simultaneously model all body wave shapes and amplitudes, thereby eliminating depth-velocity ambiguities. The data consist of western North American broadband recordings of East Pacific Rise (EPR) affiliate transform events that form a continuous record section out to $82^{\circ}$ and sample nearly the entire East Pacific Rise. The best fitting synthetics contain attenuation and small changes in lithospheric thickness needed to correct for variation in bounce point ages. The $660-\mathrm{km}$ discontinuity is particularly well resolved and requires a steep gradient (4\%), extending down to $745 \mathrm{~km}$. We find no discernible variation in apparent depths of the 405- and $660-\mathrm{km}$ discontinuities over ridge-orthogonal distances on the order of $1000 \mathrm{~km}$ (or $20 \mathrm{Ma}$ lithosphere). Body waveform comparisons indicate that we can resolve discontinuity depths to less than $\pm 10 \mathrm{~km}$, providing an upper limit to transition zone topography. These depth estimates, in conjunction with the fan shot nature of the ray paths, lower the detection limit from $S^{2}$ precursor analysis of the lateral length scale over which short-wavelength topographic variation could occur and indicate the sub-EPR Transition Zone and upper mantle are remarkably homogeneous. The lower mantle beneath the East Pacific Rise is well modeled by PREM, with the greatest variation occurring in $S c S$, reflecting strong heterogeneity along the core-mantle boundary. Together, these observations require that the East Pacific Rise spreading ridge cannot be actively supplied from the local lower mantle and that tomographically imaged lateral variation beneath the ridge likely reflects lateral smearing of outlying velocity gradients. Dynamically, the transition zone therefore appears vertically decoupled from the overlying East Pacific Rise spreading system. INDEX TERMS: 7218 Seismology: Lithosphere and upper mantle; 7207 Seismology: Core and mantle; 8121 Tectonophysics: Dynamics, convection currents and mantle plumes; 7203 Seismology: Body wave propagation; KEYWORDS: Transition zone, East Pacific Rise, mantle

Citation: Melbourne, T. I., and D. V. Helmberger, Whole mantle shear structure beneath the East Pacific Rise, J. Geophys. Res., 107(B9), 2204, doi:10.1029/2001JB000332, 2002.

\section{Introduction}

[2] According to modeled isobaric thermal gradients within rising plumes, available estimates of olivine Clapeyron slopes, and the observed global variation in upper mantle discontinuity depths, the transition zone beneath oceanic spreading centers should thin by as much as 50 $\mathrm{km}$ over lateral distances of several hundred kilometers if it is supplied directly with local lower mantle material [Moore et al., 1999; Kaula, 1983; Anderson, 1989; Agee, 1998; Bina and Wood, 1987; Akaogi and Ito, 1993; Katsura and Ito, 1989; Chevrot et al., 1999; Flanagan and Shearer, 1998; Gu and Dziewonski, 1996; Revenaugh and Jordan, 1991a]. Regional topography of this magnitude and wavelength

Copyright 2002 by the American Geophysical Union. 0148-0227/02/2001JB000332\$09.00 can be readily resolved through waveform modeling of record sections containing coherent, high-frequency, body wave triplications. Teleseismic records that individually show both core and lower mantle phases as well as upper mantle triplications uniquely constrain the entire mantle from the crust to the core-mantle boundary (CMB) along their great circle ray paths and allow one in modeling to sidestep the depth ambiguities introduced by the lithospheric high-velocity layer (the "lid") and underlying low-velocity zone (LVZ). For instance, in most forms of travel time inversion, waves propagating at shallow incidence, which might normally sample the LVZ, are instead shadowed by the lid to an extent controlled by the dimensions of both, producing an inherent ambiguity constrained only by longperiod diffractions. Teleseismic analyses, in turn, employ waves propagating at near-vertical incidence, and travel time anomalies from the LVZ and lid cancel each other, hiding 

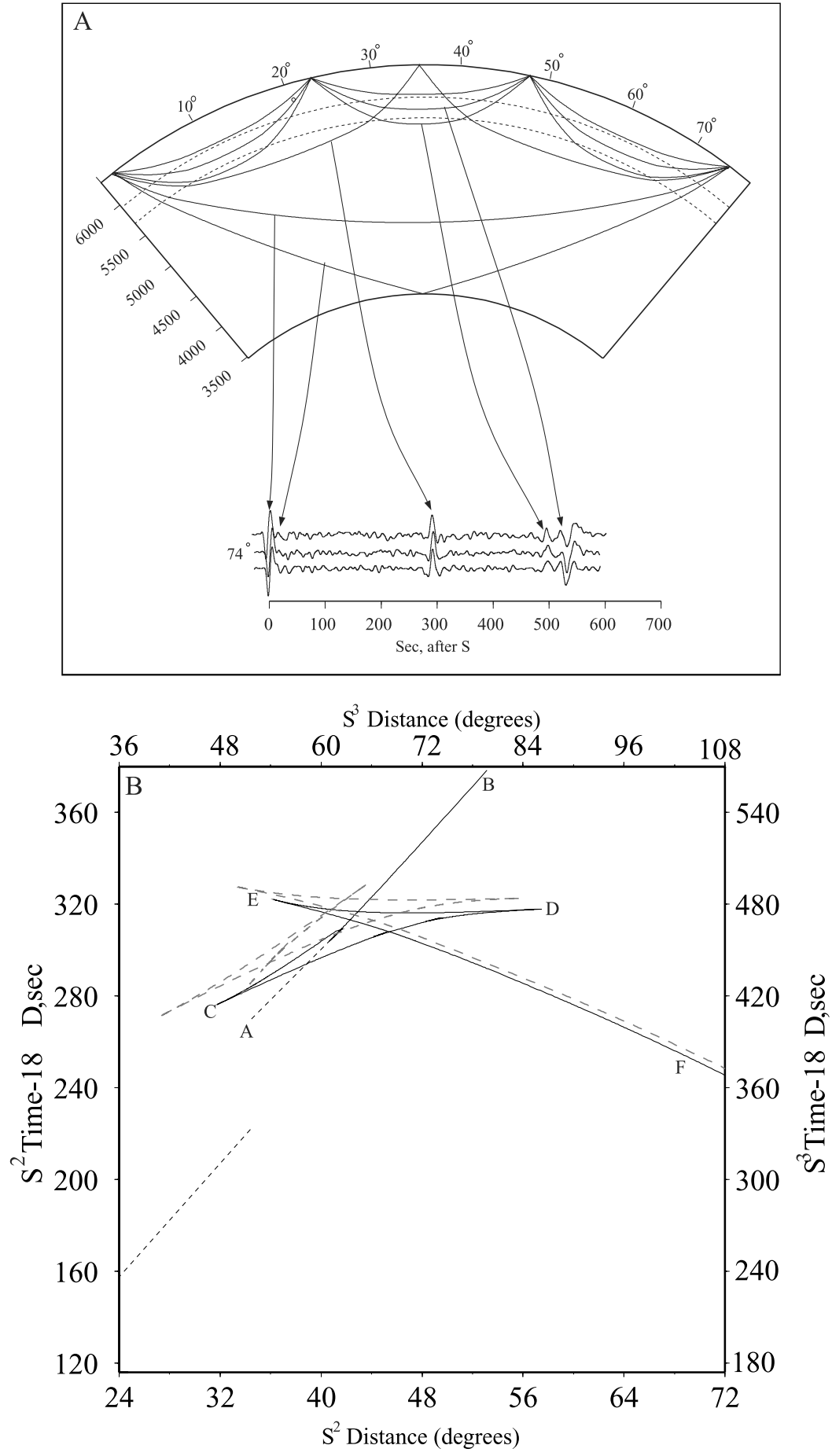

Figure 1. (a) Generalized ray paths showing discrete phases of the upper mantle triplication of multiple (in this case, triple) $S$. Doubled and tripled time separation of triplicated $S^{2}$ and $S^{3}$ subphases, respectively, facilitate their slowness identification and synthetic replication relative to $S$. For the data shown, the AB branch of the 405-km discontinuity triplication is out of range. (b) Triplication plots for the TNA model with (solid) and without (thick dashed) a lid. Fine dashed lines have been added to indicate the position of diffractions. Note that adding a lid does not greatly affect the triplications except to uniformly advance their overall travel times, leaving tripication interference patterns undisturbed.

structure in this region and prohibiting direct estimation of discontinuity depths [Allen et al., 1999].

[3] Rather than constraining absolute depths, it is instead common to assess relative variation by stacking precursors to multiple $S$ and $P$, which takes advantage of commonality in overall travel paths between the free-surface reflection and the transition zone (TZ) precursors to isolate the differential travel paths to the mantle directly above the midpoint bounce. This method has been successfully used to study transition zone topography, both globally [Flanagan and 


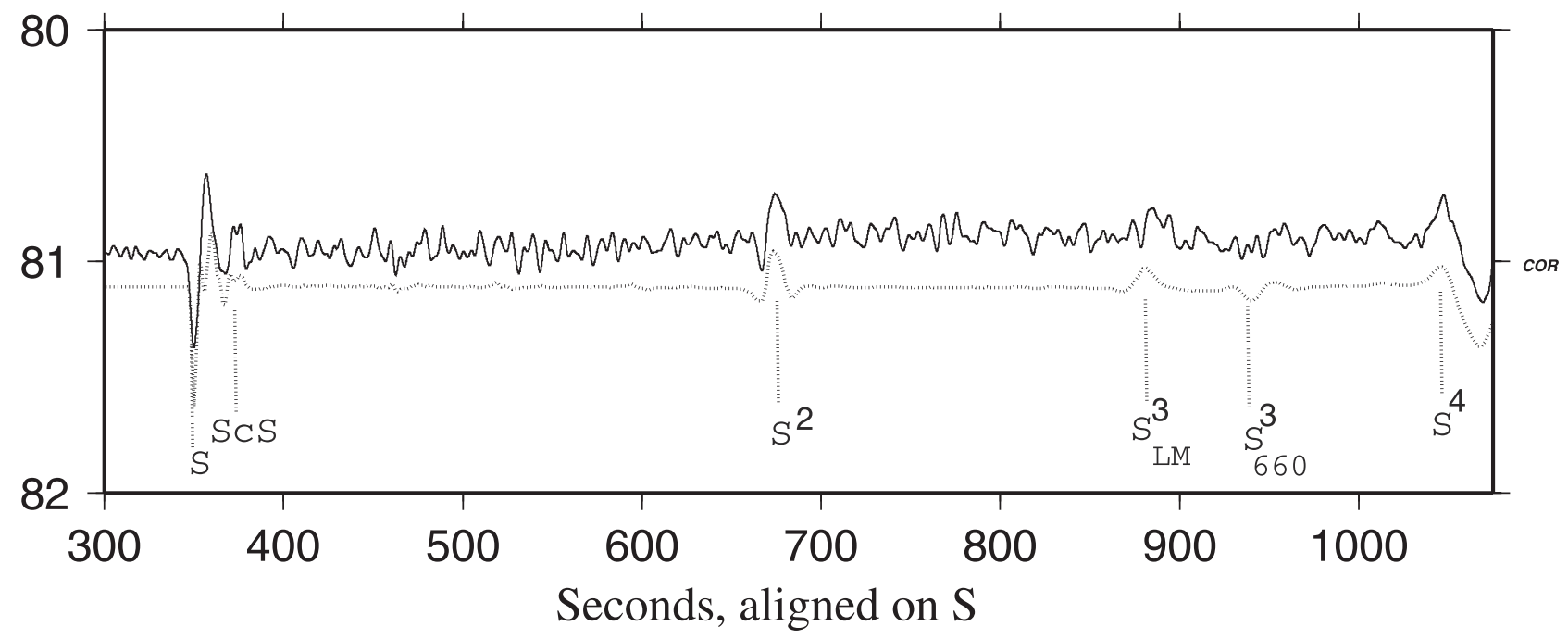

Figure 2. Seismograms in the wide-aperture record section in Figure 4 contain triplicated $S, S^{2}$, and $S^{3}$, in addition to $S c S$. Despite their teleseismic distances, the triplication phases have propagated entirely in the upper mantle. Simultaneous modeling all of phases across pure path record sections provides a unique one-dimensional model from the $\mathrm{CMB}$ to the crust free of depth-velocity ambiguities.

Shearer, 1998; Gu and Dziewonski, 1996; Shearer, 1993] and regionally, including under the near East Pacific Rise [Lee and Grand, 1996]. Effective at constraining longwavelength topography, this approach is potentially insensitive to short-wavelength topographic variation due to the frequencies of the stacked $S^{2}$ precursors commonly used in such analysis [Shearer et al., 1999; Neele et al., 1997; Chaljub and Tarantora, 1997].

[4] Unlike stacked precursor analysis, simultaneous modeling of individual body wave mantle triplications alongside lower mantle phases yields a higher-frequency, and thus more spatially localized, estimate of the whole mantle velocity profile. Over specific ranges of distances, $S$ multiples undergo triplications caused by upper mantle velocity discontinuities just as $S$ does, and the move out of the discrete branches gives the average velocities at their respective turning depths (Figures 1a and 2). For instance, at distances of $65^{\circ}-85^{\circ}$, while $\mathrm{TZ}$ structure can be inferred by replicating the triplicated $S^{3}$ branch move out across a record section, the timing of lower mantle-bottoming phases $S, S^{2}$, and $S c S$ constrain the velocity structure from the transition zone to the core-mantle boundary. Simultaneous modeling of all the body phases thus eliminates the usual velocity-depth trade-offs in model variation and can provide a unique estimate of velocity at different depths. Modeling fan shot record sections of these seismograms, in turn, yields precise estimates of lateral variation along directions perpendicular to the ray paths. Furthermore, at ranges near crossover of the direct multiple and the forward branch of the 405-km triplication (Figure 1b) the waveform shape is largely controlled by tunneled energy sampling the LVZ, which provides a means of estimating its radial structure.

[5] There are additional advantages of modeling $S$ multiples rather than direct $S$ as well, which include (1) elimination of the need for precise locations and origin times, which are not available for EPR events due to regional station density, and more importantly, (2) the time separa- tion of the individual triplication branches is correspondingly greater by a factor equal to the multiple. This feature is easily seen in the triplication plots in Figure 1b. For onedimensional (1-D) models the multiple branches are symmetric, requiring a greater span of distances to move through the interference patterns, as discussed earlier by Grand and Helmberger [1984]. By comparing the $S$ triplication branch interference with those of $S^{2}$ and $S^{3}$ over a variety of ray paths, we can easily constrain the extent of lateral variation. Ray-based construction of the triplication phases in the context of varying structure and triplication distortions are discussed in detail by Helmberger et al. [1985].

[6] In this type of analysis the primary inferences of velocity structure are based on identification of subtle triplication branches, which often appear as shoulders and relative systematic changes in the waveform shapes. Most numerical measures of fit, particularly cross correlation, miss these features and easily become contaminated by the complex onset of the Love wave. Thus the chief requirement is a dense array of seismograms with sufficiently similar ray paths such that the high-frequency triplications are coherent across the section. This proves to be a stringent requirement. Most large-aperture record sections, particularly those traversing midcontinental regions, typically show enough lateral variation to destroy the stability and coherence of the subtle triplication phases, especially at shorter periods [Burdick and Salvado, 1986]. However, for data where the broadband triplications remain coherent and individually identifiable, fine-scale constraints on transition zone lateral variation can be inferred from these phases.

[7] A disadvantage of this method is that models derived from $S$ multiples, unless combined with distributed direct $S$ results, can only be a 1-D average of the source-receiver radial plane, similar in nature to the ambiguities in $S c S$ reverberation analysis [Niu et al., 2000; Kato et al., 2001; Revenaugh and Jordan, 1991b]. Velocity anomalies local- 


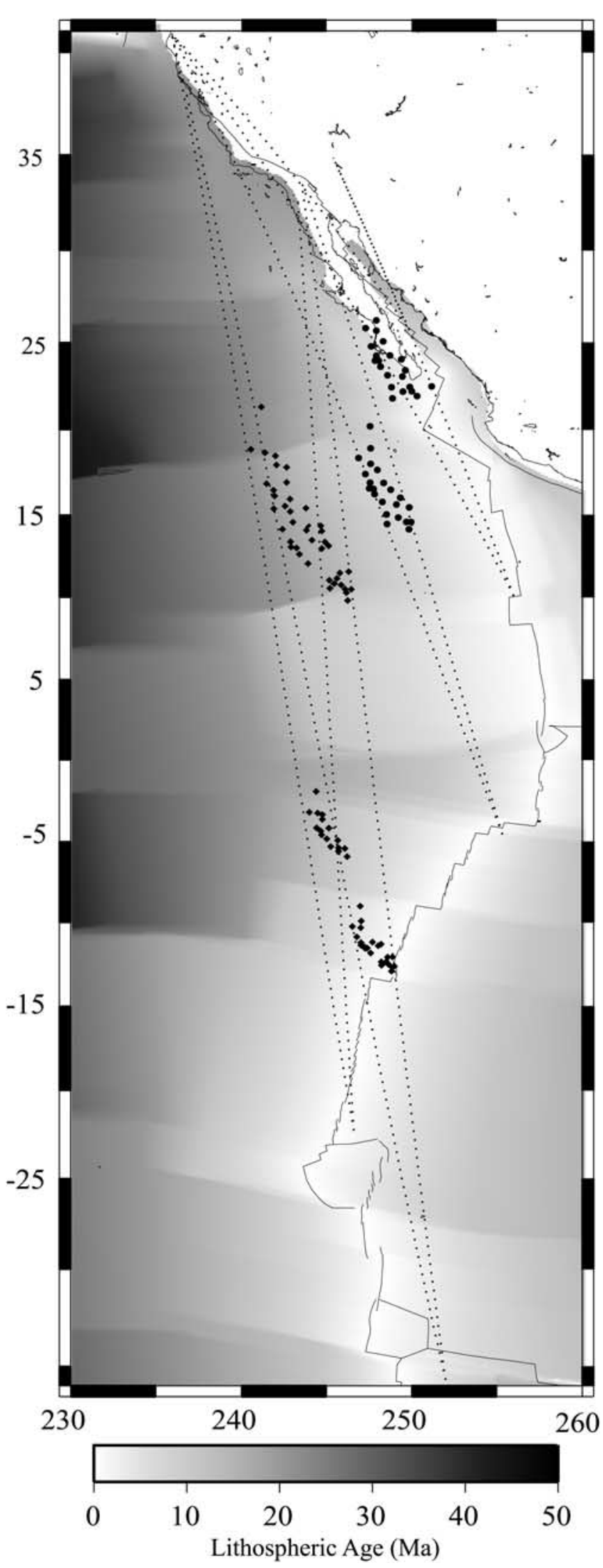

ized to a single leg of a multiple bounce phase will be interpreted as occurring along the whole ray path, which mandates an a priori knowledge that the strongest lateral variation will be normal to the ray paths. The East Pacific Rise is a suitable candidate; it is consistently imaged to be slow along its axis [Grand, 1994; VanderHilst et al., 1997; Ritsema and Heijst, 1999], with the strongest geochemical, seismic, and tectonic variation appearing orthogonal to the ridge axis [Forsyth et al., 1998]. It also provides abundant seismicity recorded on regional networks. In this paper we simultaneously model recordings of four events which together form a large aperture record section of pure paths beneath the East Pacific Rise. These records tightly constrain a unique velocity profile extending from the coremantle boundary to the uppermost mantle, which together show that the East Pacific Rise spreading center is decoupled from the underlying transition zone and lower mantle.

\section{Triplication Data}

[8] The East Pacific Rise is well sampled by an abundance of records in the range at which triplications in $S$ and its multiples can be observed. Dense deployments of broadband seismometers stretch from the Mexican to Canadian borders, and energy traversing north-south directions generate single-source record sections with extensive and identifiable phase move out. These single sources vastly facilitate unambiguous identification of the discrete triplication branches. In addition, the high level of regional seismicity along the transforms affiliated with the East Pacific Rise provides numerous events with which to image specific regional features of the oceanic ridge system.

[9] We selected four events on the basis of their location, source, and richness of triplication phases (Figure 3). For each earthquake, broadband stations from TriNet, Berkeley Digital Seismic Array, and the University of Oregon provide nearly $13^{\circ}$ of move out. Each event produces waves which traverse beneath systematically different ages of oceanic lithosphere and sample the transition zone at progressively farther distances from the sub-EPR axis region. All events are crustal strike-slip transform events that have relatively strong shear wave radiation toward the networks.

[10] Figure 4 shows the entire record section of all data used in the present study. These are transverse velocity records low-pass-filtered below $5 \mathrm{~s}$. In the following analysis, we discuss each triplication separately. Box A contains the whole $S^{3} 660-\mathrm{km}$ triplication between $58^{\circ}$ and $82^{\circ}$; box

Figure 3. (opposite) Crustal age map indicating the position of four events used to constrain lateral variation in mantle structure. Diamonds $\left(S^{3}\right)$ and circles $\left(S^{2}\right)$ indicate surface bounces for ray paths traveled by data shown in Figure 4. Shading density indicates plate age. The most distant event traverses on average beneath 13 Ma lithosphere located on average $1200 \mathrm{~km}$ from the topographic expression of the East Pacific Rise axis, while the closest event traverses beneath $2 \mathrm{Ma}$ and younger crust located nearly beneath the EPR axis. 


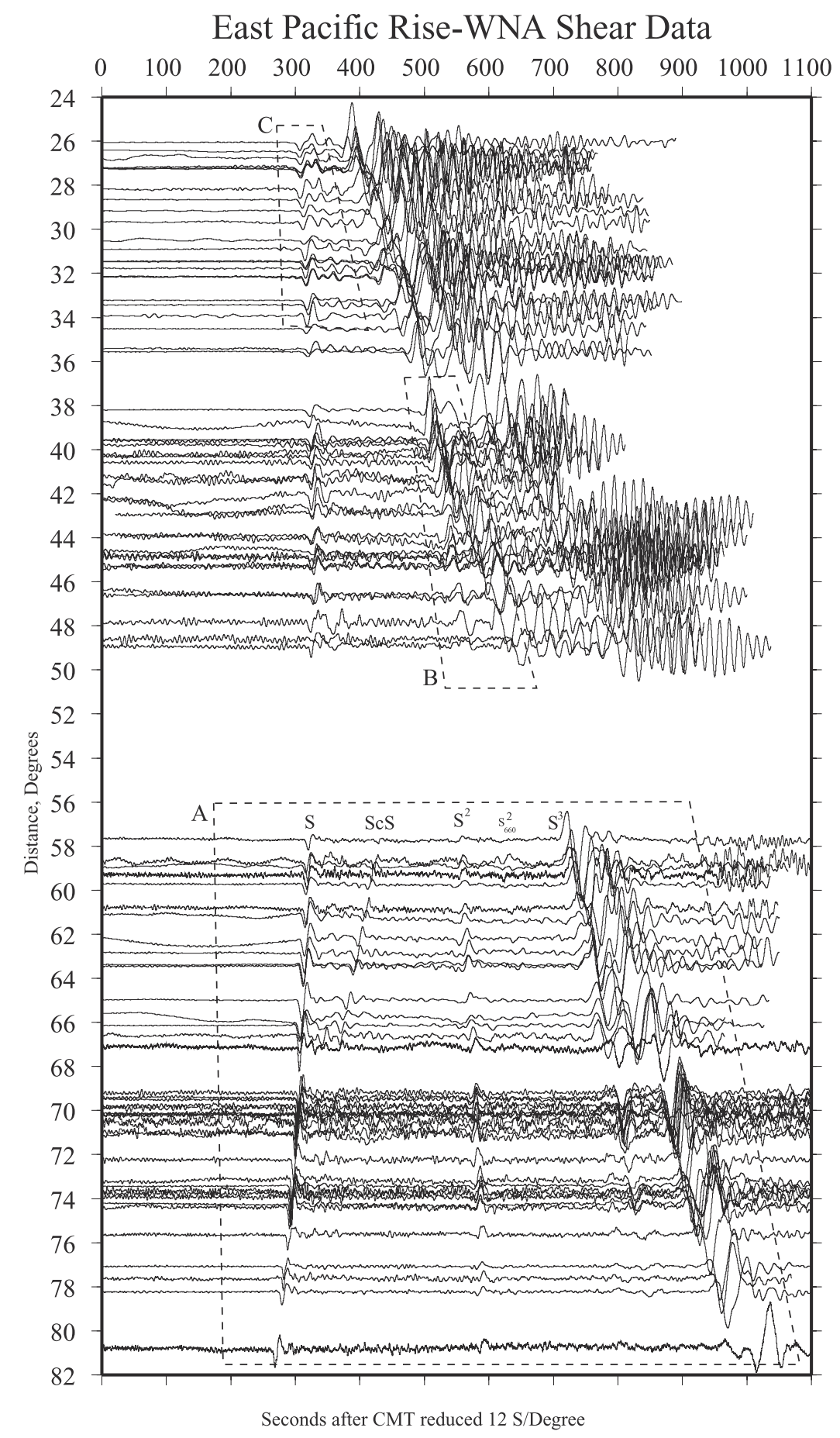

Figure 4. East Pacific Rise shear waveforms in velocity recorded on North American west coast (WNA) broadband networks. Effective aperture of the combined arrays provides upward of $13^{\circ}$ of phase move out per event. Data are low-pass-filtered below $5 \mathrm{~s}$. The key structural interpretations are based on modeling of the data shown in boxes; box A contains the $S^{3}$ 405- and 660-km triplications; box B contains the $S^{2} 660-\mathrm{km}$ triplication; box C contains branch D of the $S 660-\mathrm{km}$ triplication.

B contains the $S^{2}$ triplication between $38^{\circ}$ and $49^{\circ}$; box C contains the $S$ triplication between $26^{\circ}$ and $32^{\circ}$.

\subsection{Waveform Modeling}

[11] Triplicated waveform shape is controlled in part by tunneled energy traversing the LVZ, requiring synthetics based on complete solutions rather than ray-based approx- imations. We use the frequency-wave number (FK) double integration approach of Bouchon [1981], where we account for attenuation by making the velocities complex, using the method of Saikia [1994]. We also employ the EPR-specific attenuation model of Ding and Grand [1993], which greatly improves the relative amplitude fits over synthetics computed without an attenuation model. A modified form of 


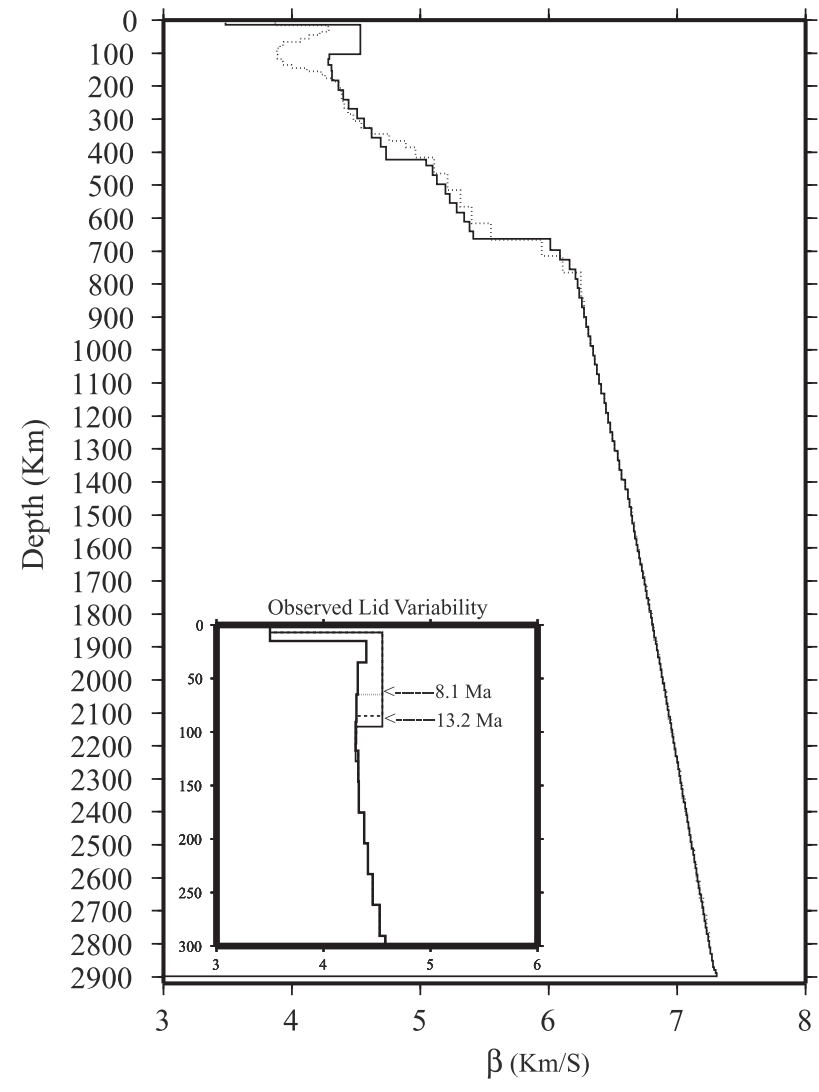

Figure 5. Unique sublid to core-mantle boundary 1-D East Pacific Rise model (EPRM) shear structure used to model all observations of triplicated $S^{3}$, independent of distance from East Pacific Rise ridge axis (solid line). The 255-km-thick transition zone structure adequately accounts for all observed triplication data in Figure 3. Model derived from MELT OBS [Forsyth et al., 1998] event 345/95 is shown (dotted). Inset shows progressively older sampled plate mandates use of thicker lithospheric lid. Tectonic North America is shown as solid line.

tectonic North America (TNA) [Grand and Helmberger, 1984] overlies a PREM-like lower mantle [Dziewonski and Anderson, 1981] above $660 \mathrm{~km}$ depth (Figure 5). Tectonic North America was derived from East Pacific Rise events recorded in western North America but excluded coastal stations and therefore did not include purely oceanic paths, which is reflected in its lack of a significant lithospheric lid. This can be observed in the synthetics of Figures 6 and 7 , computed without and with a lid, respectively. In Figure 6, showing the synthetics corresponding to the top half of box A from Figure 4 aligned on $S$, the synthetic $S^{2}$ and $S^{3}$ both arrive late, with $S^{3}$ systematically arriving later than $S^{2}$, in some traces by up to $10 \mathrm{~s}$. While there are a number of ways to remedy this, adding a high-velocity lid is particularly effective, for two reasons. First, $S^{2}$ and $S^{3}$ all leave the source at shallower angles than does direct $S$, so they spend relatively more time traversing the lid, and second, each multiple of $S$ adds two extra lid crossings, while $S$ only samples it at the source and receiver, amplifying the first effect. Differential $S$ multiple timing is thus more strongly influenced and accounted for by perturbations to the shal- low lithospheric structure than is the timing between triplication branches of a particular multiple. By the same token, velocity perturbations at depths below the lid but above the transition zone cause a similar distortion of $S^{2}-$ $S, S^{3}-S$, and $S^{3}-S^{2}$ timing which decreases with increasing range. Perturbations to the TNA model decrease the waveform fits, and through experimentation we have concluded that TNA modified to contain a lid is the best fitting model for these propagation paths. It should be noted that the sharpness of the lid-LVZ boundary (the G discontinuity) is not resolved with this data set. If this structure represents a thermal boundary layer, as is commonly assumed [Anderson, 1989], then most likely it is not as sharp a delineation as is shown in Figure 5. However, ScS reflections off the G discontinuity under $100 \mathrm{Ma}$ Pacific and 40 Ma Phillipine plate regions have shown it to be sharp, incompatible with thermal cooling but likely representing a compositional boundary [Gaherty et al., 1999b]. Radially smearing the $\mathrm{G}$ discontinuity in the models in Figure 5 over several tens of kilometers holding vertical travel times fixed has little effect on the synthetics, so for the purposes of imaging deeper structure the $G$ structures shown in Figure 5 suffice.

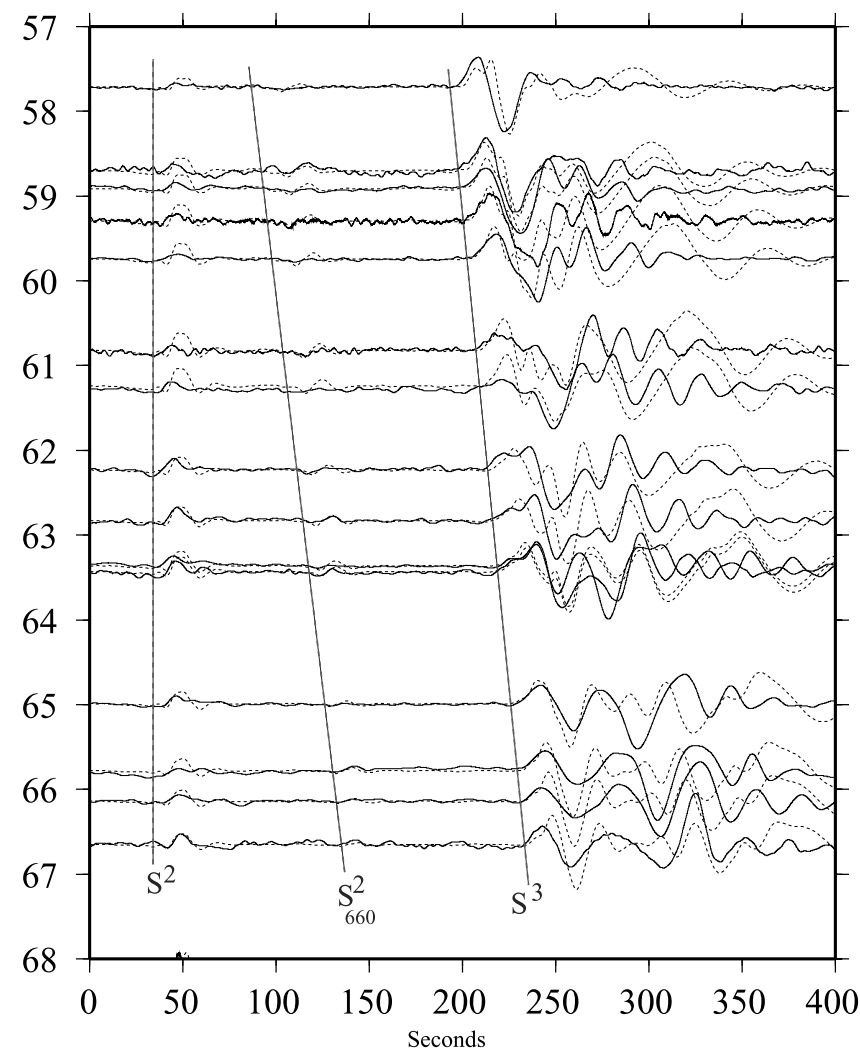

Figure 6. Triplicated $S^{3}$ synthetics computed for tectonic North America model, which was derived from paths away from oceanic crust and therefore does not fit oceanic paths. These data are aligned on $S$, and without a lid both the $S^{2}$ phase and the triplicated ensemble of $S^{3}$ are late by upward of $10 \mathrm{~s}$ due to both their shallower path within the lid and their multiple sampling at surface bounces. With ray parameters similar to $S$, relative $S c S$ timing at these ranges is insensitive to lid thickness. 


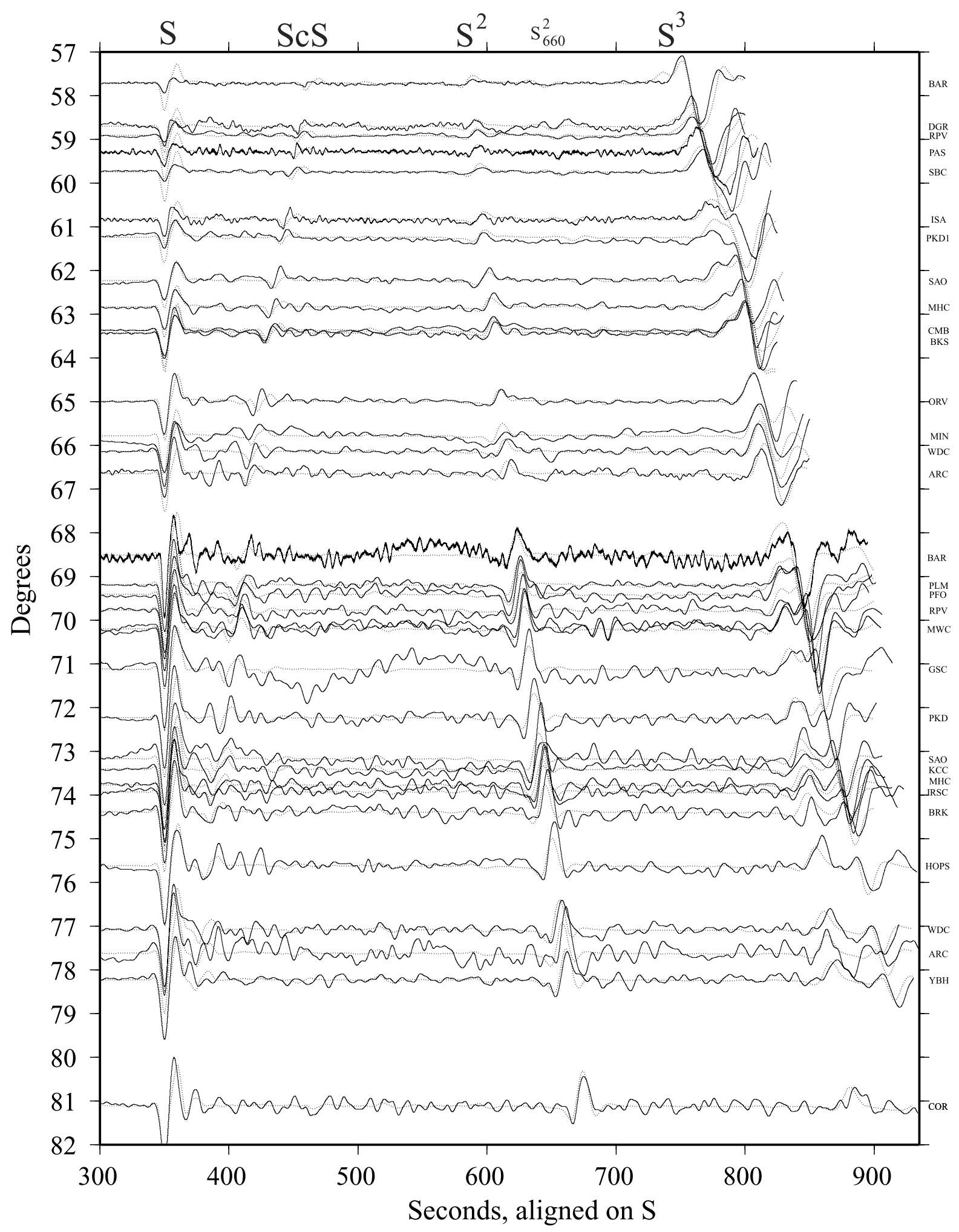

Figure 7. Modeled waveforms containing $S, S c S, S^{2}$, and triplicated $S^{3}$, aligned on $S$. Regional transition zone thickness variation would be manifested as systematic misfit in subphases of the $S^{3}$ triplication, which is not observed. Resolution tests of our ability to assess lid thickness are shown in Figure 8. These data are fit with three different lithospheric lid thicknesses $\left(V_{s} 4.55 \mathrm{~km} / \mathrm{s}\right)$ shown in Figure 5 (inset). At $57^{\circ}-61^{\circ}$ (sampling oceanic plate with age $12 \mathrm{Ma}$ ), the synthetics are computed with a lid of $73 \mathrm{~km}$, which grows to $76 \mathrm{~km}$ for data between $62^{\circ}$ and $66^{\circ}(13 \mathrm{Ma})$. At ranges of $68^{\circ}-78^{\circ}$ the modeled lid thickness is 58 $\mathrm{km}$ thick, reflecting the first surface bounce near the East Pacific Rise ridge crest. The largest misfit in the record section is the $S c S$ phase on stations ARC, WDC, MIN, and ORV, which reflects heterogeneity in D" (see text). The seismogram from station BAR at $68.5^{\circ}$ is unfiltered. 


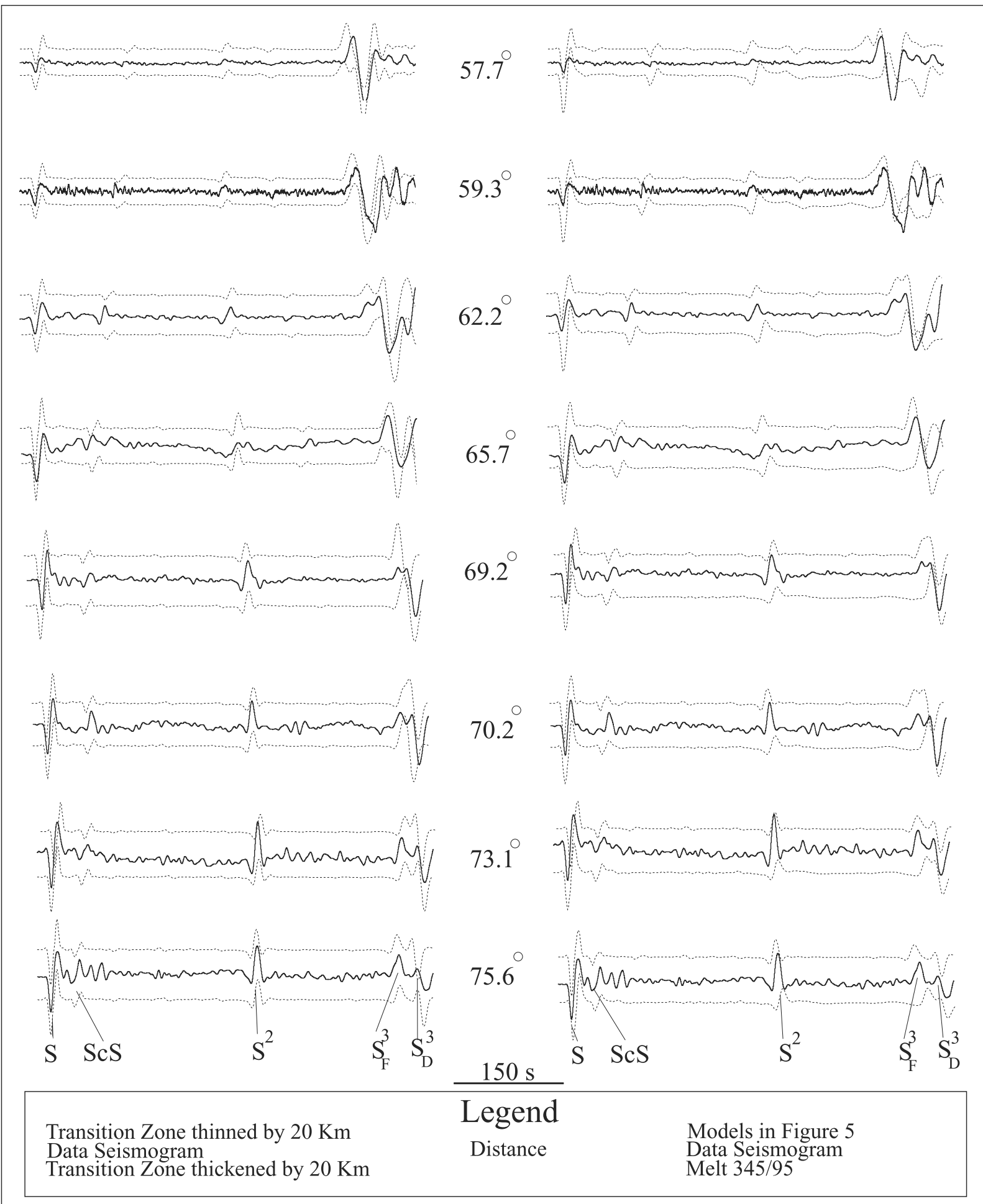

Figure 8. Comparison of other models with the $S^{3}$ data. The triplication branches are labeled indicating the crossing of the CD by the F branch of the $660-\mathrm{km}$ triplication. The data are repeated twice at each range; upper right synthetics are our preferred model; lower right is model 345/95 from the recent MELT OBS experiment, derived from subaxial ray paths; top left shows synthetics for a transition zone decreased in thickness by $20 \mathrm{~km}$, bottom left for a $20-\mathrm{km}$ increase in thickness. The crossover of the various phases through the record section cannot be replicated with either of the TZ perturbation models. MELT model 345/95, derived for energy traveling directly under the EPR axis, is significantly slower than the off-axis data discussed here. 


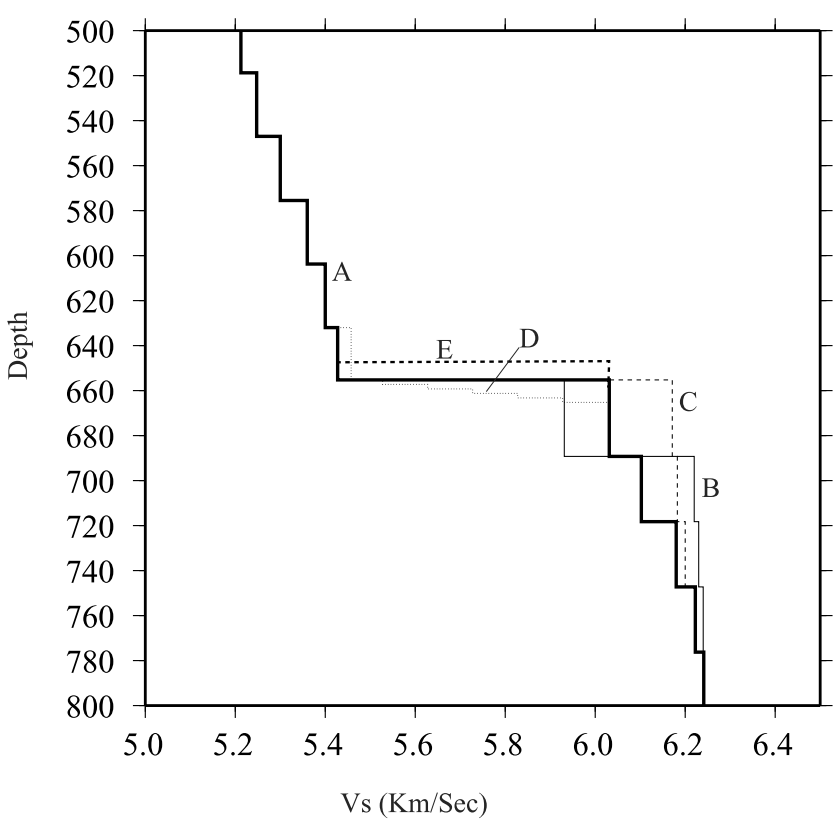

Figure 9. Plots of the $660-\mathrm{km}$ discontinuity structure perturbations with the corresponding waveform fits displayed in Figure 10: model A, the preferred model shown also in Figure 5 for reference; model B, mapping 30\% of the $660-\mathrm{km}$ discontinuity into sub-660-km structure, thus removing the high-velocity gradient; model $\mathrm{C}$, increasing the discontinuity jump and removing the underlying gradient; model $\mathrm{D}$, linearly mapping the discontinuity over $25 \mathrm{~km}$ radially; and model $\mathrm{E}$, raising the discontinuity to $650 \mathrm{~km}$. Model letters correspond to synthetics profiles of Figures $10 \mathrm{a}-10 \mathrm{e}$.

[12] In contrast to $S$ multiple move out, for records within triplication ranges, variability at transition zone depths primarily affects the relative timing of the individual triplication branches and therefore their interference pattern within a given packet across a record section but has significantly less effect on the multiple- $S$ differential timing. This dependence allows us to isolate influences of the lid from those of the transition zone in modeling the records. The effect can be seen in Figure 1b, where the lid moves the triplication as a whole but does not significantly change the crossover distances. For these data, allowing some small changes in lid thickness proves effective in handling the small timing shifts encountered at the various bounce points displayed in Figure 3.

\subsection{Triplicated $S^{3}$}

[13] In the following waveform analysis, we will generally refer to the triplication branches by single letters which denote the two geometric arrivals forming the cusp designated by the letter, as labeled in Figure $1 \mathrm{~b}$. The 405- and $660-\mathrm{km}$ triplications in $S^{3}$ are first observable together near $57^{\circ}$ and extend through $82^{\circ}$ (displayed in box A, Figure 4). At distances less than $57^{\circ}$, the body waves have not yet separated from the later arriving Love waves. Beyond $57^{\circ}$ (Figure 7), the B branch of the $405-\mathrm{km}$ triplication and both the $\mathrm{E}$ and $\mathrm{D}$ branches of the $660-\mathrm{km}$ triplication are observed and can be modeled.
[14] Each of the two free surface bounces of $S^{3}$ Hilbert transforms the source, such that the $S^{3}$ waveform is approximately the negative of $S$. At $57.6^{\circ}, S^{3}$ has a simple shape, similar to the inverted direct $S$ phase, but longer period due to the interference between the crossing $\mathrm{A}-\mathrm{B}$ (uppermost mantle turning) branch of the $405-\mathrm{km}$ triplication and the TZ-turning $\mathrm{C}-\mathrm{D}$ branch. With increasing distance through $59.7^{\circ}$ (station SBC) the simple pulse thickens predictably as the two branches move apart after crossover. This pulse broadening is duplicated in the synthetics, which also show that computed crossover lies closer than $57^{\circ}$, fitting the data.

[15] Starting at $59.4^{\circ}$ and extending beyond $80^{\circ}$, the 660 $\mathrm{km}$ triplication develops cleanly, with both the E and D branches clearly coherent across the record section. At $59.4^{\circ}$ (PAS) the onset of the $660-\mathrm{km}$ triplication is observed as a bulge on the bottom of the downswing following the 405$\mathrm{km}$ pulse (PAS, SBC; Figure 7). This nascent 660 branch is clearly separated by $61^{\circ}$ (PKD, ISA) and grows larger in amplitude and moves forward in timing to become the largest arrival at $63.5^{\circ}(\mathrm{CMB}, \mathrm{BKS})$. By $65^{\circ}(\mathrm{ORV})$ it has overtaken and merged with the TZ-turning CD branch, pulling ahead by $69.2^{\circ}$ (PLM). Crossover occurs at approximately $66^{\circ}$ in the data. The separation between the first arriving $\mathrm{F}$ branch and the fading D cusp of the 660 branch is visible out past a remarkable $80^{\circ}$; despite the teleseismic distances, these phases have propagated entirely in the upper mantle.

[16] The synthetics overlaid (dotted) on the data in Figure 7 are computed with the model in Figure 5. Remarkably, essentially the full section, including $S, S c S$, $S^{2}$, and the triplicated waveforms of $S^{3}$ are reproduced with this $1-\mathrm{D}$ velocity model. A comparison with records containing phases traversing continental interior or margin paths contrasts the relative shear speed homogeneity evidenced by these waveforms (e.g., Melbourne and Helmberger [2001] or Burdick and Helmberger [1978]). The only substantial modification to TNA lies in the thickness of the lithospheric lid as a function of plate age. Throughout this profile, the synthetics for the model fit the data consistently better than any particular perturbation to the model. For instance, the travel time "twinkling" of the triplicated arrivals in the form of alternating early $(660 \mathrm{D}$ branch at $62.2^{\circ}, 66.7^{\circ}$, and $\left.77.8^{\circ}\right)$ or late $(660 \mathrm{D}$ branch at $69.8^{\circ}$ and $61.2^{\circ}$ ) phases is not systematic in the sense that would indicate regional change in the TZ. For waveforms aligned on $S$ a gradual TZ thinning with distance from the the ridge axis would produce at records closer than $67^{\circ}$ a consistently early arriving 405 branch and a late 660 branch compared with records beyond $67^{\circ}$, which come from a separate event whose waves travel nearly beneath the East Pacific Rise.

[17] Although the stability of the triplications alone indicates little significant lateral variation, we can test synthetic fits from models with perturbed transition zone structure to quantify our resolution. Figure 8 shows synthetics from the model of Figure 5 (the preferred model, EPRM), the relevant model from the recent MELT experiment [Forsyth et al., 1998], and two models containing 10$\mathrm{km}$ shifts of the $405-$ and $660-\mathrm{km}$ discontinuities to produce a transition zone which varies $\pm 20 \mathrm{~km}$ in thickness. The lefthand column of Figure 8 shows the data with synthetics 

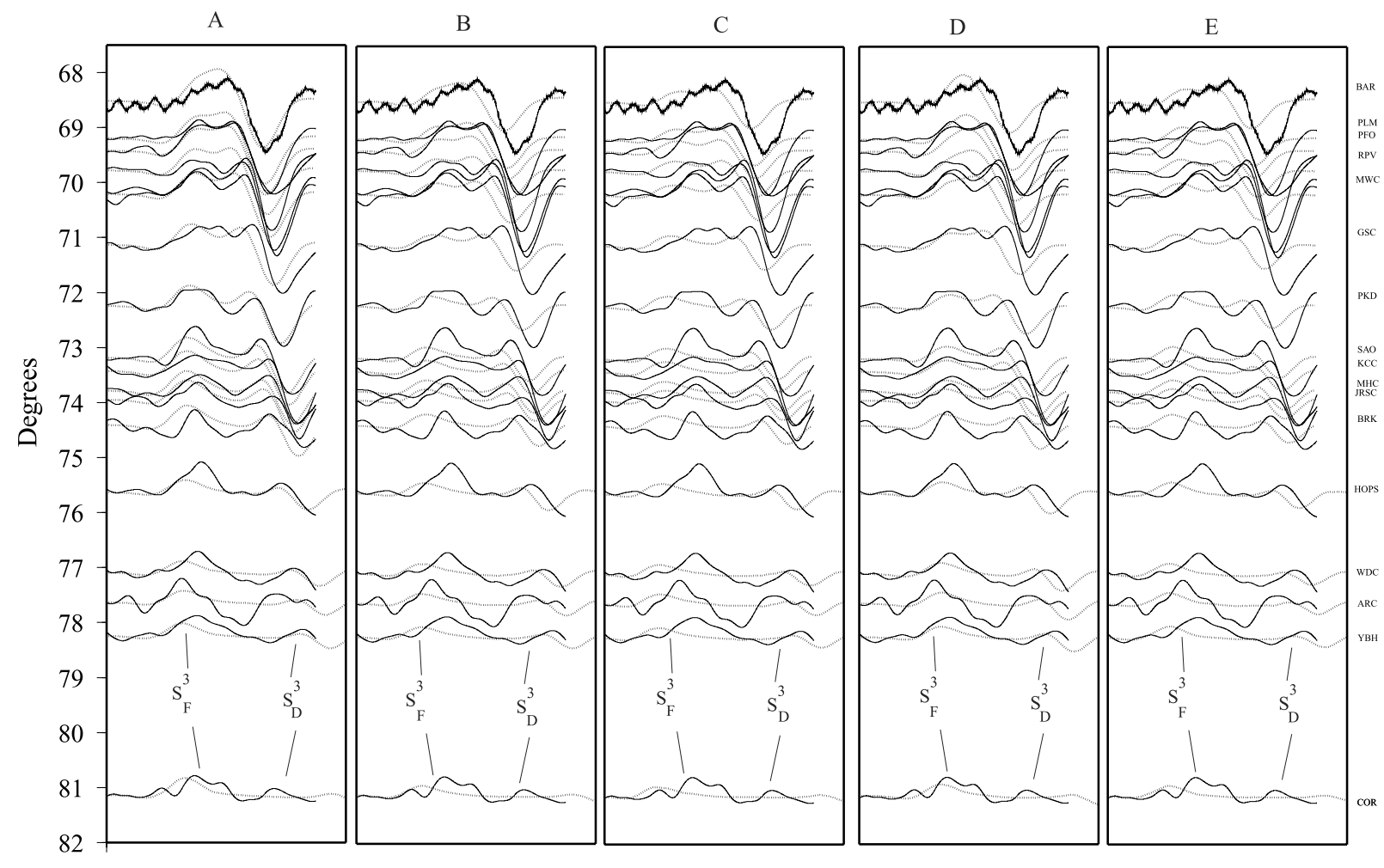

$50 \mathrm{~S}$

Figure 10. The 660-km triplication phases of $S^{3}$ for alternate discontinuity fine structures, aligned on $S$. These models, shown in Figure 9, produce substantially different waveform fits. (a) Model 1, preferred model, requires the linear gradient to $740 \mathrm{~km}$ depth; (b) model B advances the F branch of the $660-\mathrm{km}$ triplication $10+\mathrm{s}$ beyond that called for by the data; (c) model $\mathrm{C}$ overly exaggerates the F-D subphase time separation; (d) model $\mathrm{D}$ advances the $\mathrm{F}$ branch arrival, again altering the style of F-D phase interference observed in the data between $68^{\circ}$ and $72^{\circ}$, as well as overly advancing the back branch of the $660-\mathrm{km}$ reflection beyond $72^{\circ}$. (e) model E, raises the discontinuity by $10 \mathrm{~km}$ both, destroying the F-D interference as well as the time separation between the two triplication phases. See text for further analysis of waveform perturbations.

from a $20-\mathrm{km}$ thinner $\mathrm{TZ}$ on top and $20-\mathrm{km}$ thicker $\mathrm{TZ}$ on the bottom.

[18] Our ability to differentiate between these models is based on both the changes in the timing of the $S^{3}$ arrival and the position of crossover in the $660-\mathrm{km}$ triplication, as reflected in the waveform shape. In the top left set of synthetics corresponding to a $20-\mathrm{km}$ thinner TZ, crossover is consistently misplaced from the data. At $57.7^{\circ}, S^{3}$ is early in the top calculation, while in the bottom trace the back branch of the $405-\mathrm{km}$ triplication has already split away from the TZ-turning energy, which is not observed in the data. At $75.6^{\circ}$ the thinner TZ synthetics show cleanly split $S^{3}$, but the separation of the $\mathrm{CD}$ (TZ turning) and F (lower mantle turning) branches is too small by $\sim 5 \mathrm{~s}$. The thicker transition zone synthetics at this distance show a better separation, but the crossover badly misfits the data (e.g., $70.2^{\circ}$ ). Through modeling of this record section, we judge our resolution of the TZ discontinuities with $S^{3}$ to be under $10 \mathrm{~km}$. Variation beyond this amount in the TZ structure would be systematically observed in the record section.

[19] Overall, velocities at all depths in MELT model 364/ 95 (lower right-hand side of Figure 8) [Forsyth et al., 1998] are too slow for these waveforms. Relative to $S, S^{2}$ is consistently late by $5-10 \mathrm{~s}$ across all traces, and triplicated $S^{3}$ is late by upward of $20 \mathrm{~s}$. The crossover of the D and F branches of the $660-\mathrm{km}$ triplication is also off by over a degree. MELT event 364/95 propagated precisely under the EPR axis, so the reported ultralow mantle velocities (3.7 $\mathrm{km} / \mathrm{s}$ ) reflecting partial melt must be confined to a narrow region directly under the ridge, as explored but not detected by Hung et al. [2000].

[20] The coherence on over 20 traces of the $660-\mathrm{km}$ discontinuity reflection and the sub-660-km turning $\mathrm{F}$ branch of the triplication provides an opportunity to study the magnitude of the $660-\mathrm{km}$ velocity jump as well as the details of the higher-velocity gradient directly below it. The depth extent of this feature is a key constraint for the thermodynamics of the olivine disassociation reaction but is difficult to infer from the frequency content of $S^{2}$ precursor analysis, and its radial extent has been difficult to establish firmly [Flanagan and Shearer, 1998; Shearer, 1993].

[21] Figure 9 shows several alternate models of the near-660-km structure, while Figure 10 contains their corresponding synthetics with data. In Figures 9 and 10, 


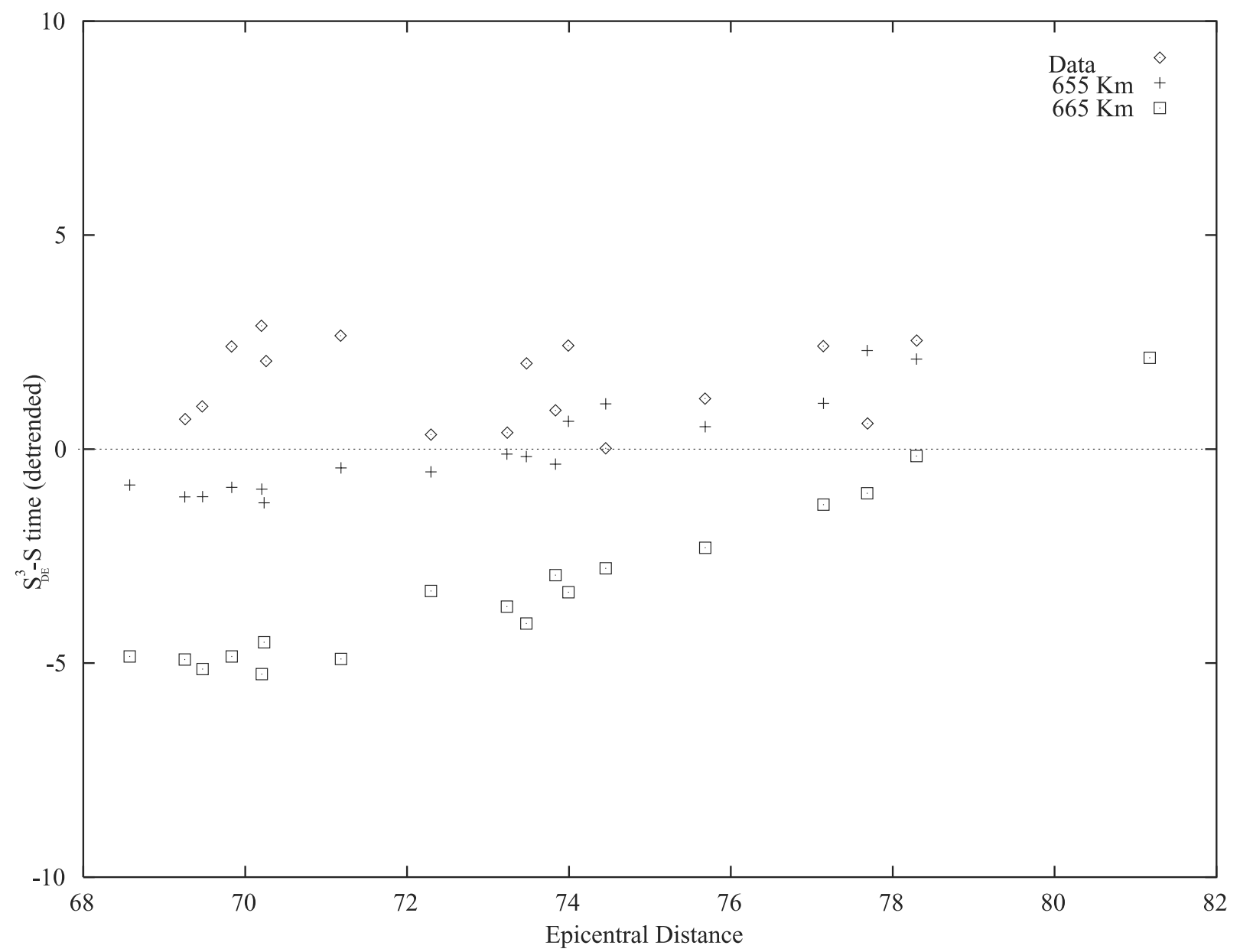

Figure 11. $S-S^{3}(660-\mathrm{km}$ reflection) phase picks. Data are represented by diamonds, those from the preferred model (Figure 5) synthetics by crosses, and synthetics with the 660-km discontinuity lowered to $670 \mathrm{~km}$ by squares. Picks are reduced in time by subtracting $7.5 \mathrm{~s}$ per degree of distance from each $S_{660}^{3}-S$ delay measurement and show that a $10-\mathrm{km}$ displacement of the $660-\mathrm{km}$ reflection is not warranted by the data.

model $\mathrm{A}$ is the model of Figure 5 and is used to compute synthetics in Figure 7, models $\mathrm{B}$ and $\mathrm{C}$ show alternative structures which remove the high-velocity gradient directly beneath $660 \mathrm{~km}$ but maintain the TZ and lower mantle velocities needed to satisfy the $660-\mathrm{km}$ triplications, model D contains a nonsharp $660 \mathrm{~km}$ spread out over $10 \mathrm{~km}$ radially, and model $\mathrm{E}$ has the discontinuity raised to 650 $\mathrm{km}$, appropriate for negative olivine Clapeyron slopes in a hotter than average region. The timing and nature of 660 $\mathrm{km}$ discontinuity subphase interference disqualify the alternative models; in model B both subphases arrive early, in model $\mathrm{C}$ the timing of the $660-\mathrm{km}$ reflection relative to the sub-660-km turning energy causes the phases to interfere destructively in the synthetics rather than constructively as in the data; model D has smaller amplitude sub-660-km turning energy, which does not fit the data as well as model A, indicating that the $660-\mathrm{km}$ discontinuity is, in fact, sharp $(<10 \mathrm{~km})$. Model $\mathrm{E}$ contains early arrivals on both subphases, showing that a $10-\mathrm{km}$ raising of $660 \mathrm{~km}$ to $650 \mathrm{~km}$ is inappropriate.

[22] $S_{660}^{3}-S$ time also provides a measure of the data's sensitivity to $660-\mathrm{km}$ topography. Figure 11 contains data and synthetic pick residuals in reduced time for models $\mathrm{A}$ and $\mathrm{E}$ above, computed by subtracting $7.5 \mathrm{~s}$ per degree of distance from each $S_{660}^{3}-S$ versus range profile. This demonstrates that a $10-\mathrm{km}$ displacement of the $660-\mathrm{km}$ discontinuity to $670 \mathrm{~km}$ is not warranted by any of the traces in the record section, despite their sampling significantly different transition zone structures.

\subsection{Lower Mantle}

[23] Although the records shown in Figure 7 are aligned on $S, S^{2}$ turns in the lower mantle and $S c S$ samples the entire mantle, yielding constraints on variability beneath the transition zone. In general, the synthetics computed for PREM below $745 \mathrm{~km}$ depth fit these arrivals well, with little systematic variation inferable across the section. $S c S$ shows the most scatter and waveform instability, particularly between $65^{\circ}$ and $72^{\circ}$, where synthetic $S c S$ varies by up to $10 \mathrm{~s}$ late and early across 10 sequential stations (ORV-PKD). These records, as well as those beyond $72^{\circ}$ (PKD-JRSC), also contain one or more evanescent phases preceding the primary core reflection. These phases evidence the short-wavelength velocity heterogeneity known 


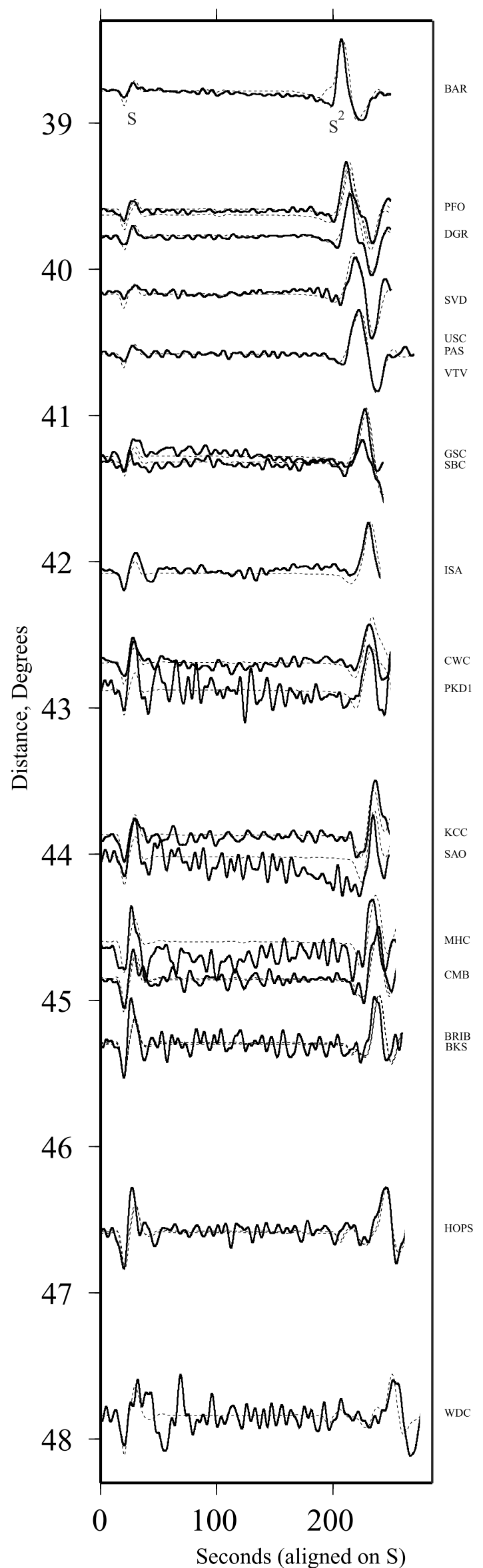

to exist along the core-mantle boundary in these regions (many references, e.g., Garnero and Helmberger [1996] and Ding and Helmberger [1997]) but cannot be modeled with the station density shown in Figure 7. However, broadband seismic networks currently under development in southern California and Japan will yield sufficient waveform density that these phases will be tractable with 3-D synthetics.

[24] $S^{2}$ in Figure 7 shows greater stability and less scatter than $S c S$, but there are some notable timing discrepancies. From $57^{\circ}$ through $65^{\circ}, S^{2}$ is well predicted by synthetics but becomes early near $66^{\circ}$ and varies between early and on time through the remainder of the section. It is difficult to say whether these are deep mantle or receiver-side effects, but they are probably the latter due to the systematic manner in which they vary. The potential for lithospheric lateral variation beneath the continental margin to influence $S^{2}-S$ differential times can be seen in Figure 6, and moreover, differential $S^{2}-S$ travel time anomalies of up to $18 \mathrm{~s}$ across equidistant stations near $30^{\circ}$ in coastal and eastern California have been shown elsewhere to be caused by rapidly varying lid thickness [Melbourne and Helmberger, 2001]. In Figure 7, coastal stations such as Arcata, California $\left(66.7^{\circ} ; 77.5^{\circ}\right)$, and Berkeley, California $\left(74.5^{\circ}\right)$, consistently show the greatest misfit among both $S^{2}$ and $660-\mathrm{km}$ triplicated $S^{3}$, consistent with anomalous lid thickness beneath the California plate margin, rather than transition zone discontinuity topography or mid-upper mantle variability. Of course, highfrequency topography along the 405- or $660-\mathrm{km}$ structures similar to that reported beneath the Yellowstone hot spot (30 km radial variability over $200-300 \mathrm{~km}$ horizontally along the 405-km discontinuity [Dueker and Sheehan, 1997]) would not be inferable from this data set, but could contribute to the observed misfit.

\subsection{Triplicated $S^{2}$}

[25] Relative to the $S^{3}$ data, the events containing triplicated $S^{2}$ (box B in Figure 4) sample transition zone mantle with average distances of nearly $750 \mathrm{~km}$ from the transition zone lying directly beneath the topographic axial high which forms the East Pacific Rise, or close to $500 \mathrm{~km}$ closer than the $S^{3}$ data. These data are best modeled with the same transition zone structure as the $S^{3}$ (Figure 5), and perturbations to the model systematically degrade synthetic fits across the record section.

[26] The $S^{2}$ triplication (Figure 12) is first observed at $38.7^{\circ}$ and extends through the D branch of the $660-\mathrm{km}$ triplication at $48^{\circ}$. The large amplitude of $S^{2}$ relative to $S$ at $38.7^{\circ}$ is due to the constructive interference at crossover of the 405 branch and the shallow mantle branche; by illustration, compare this with data at $42^{\circ}$. The $\mathrm{C}$ branch of the $405-\mathrm{km}$ triplication is visible as a shoulder, decaying on the right side of the $S^{2}$ phase between $39^{\circ}$ and $41^{\circ}$, particularly

Figure 12. (opposite) Comparison of $S^{2}$ observations (box B) with synthetics (dotted) appropriate to the model in Figure 4 and the $8.1 \mathrm{Ma}$ lid. These ray paths travel on average $750 \mathrm{~km}$ from EPR axis but show transition zone shear structure identical to that observed along ray paths $1200 \mathrm{~km}$ from the EPR axis. 


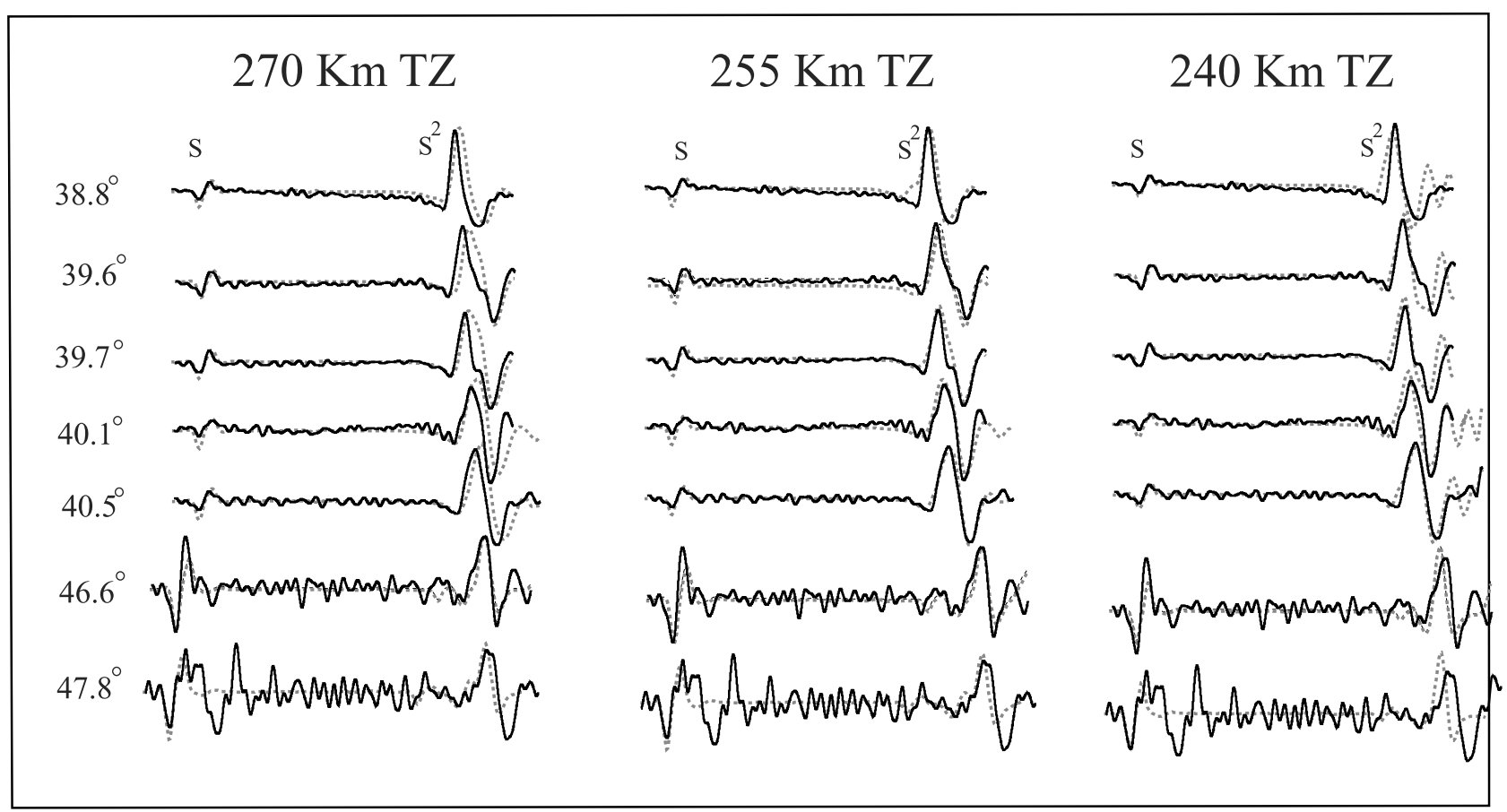

Figure 13. Varying transition zone thickness by $15 \mathrm{~km}$ from the best fitting $S^{3}$ model, producing misfit in the $S^{2}$ arrival time and waveform shape as observed. Increasing TZ thickness by $15 \mathrm{~km}$ retards the $S^{2}$ arrival at closer distances $\left(38^{\circ}-40^{\circ}\right)$, while thinning the TZ by the same amount overly advances the arrival beyond $40^{\circ}$. Best fitting transition zone is not discernibly different than that for the $S^{3}$ data traveling $1200 \mathrm{~km}$ from the ridge axis.

on stations PFO and DGR. Near $41^{\circ}$ it is difficult to distinguish between the fading $\mathrm{B}$ branch of the $405-\mathrm{km}$ triplication and the rising E branch of the $660-\mathrm{km}$ triplication, as their expected arrival times are similar. Between $41^{\circ}$ and $43^{\circ}$, the E branch of the $660-\mathrm{km}$ triplication grows in amplitude and moves forward to cross the CD branch near $44^{\circ}$. ISA $\left(42^{\circ}\right)$ shows a well-developed $\mathrm{E}$ arrival that is not apparent on PKD1 or CWC, but near $44^{\circ}, \mathrm{KCC}$ has a much larger $S^{2}$ amplitude, as does SAO. From $39^{\circ}$ through $42^{\circ}$ the amplitude of $S^{2}$ decreases as the two branches move apart, and then rather than decaying further with range, beyond $42^{\circ}$ the amplitude rises slightly at $44^{\circ}$ as the CD and $\mathrm{F}$ arrivals cross. Beyond $45^{\circ}$ the amplitude then drops off again quickly as these two phases move apart.

[27] The synthetics shown in Figure 12 are calculated for the same whole mantle structure shown in Figure 5 and used for the more distant $S^{3}$ data, but with a lid thickness appropriate for 8.1 Ma crust; see inset in Figure 5. With this modification the synthetics match the data both in terms of the separation timing between $S$ and $S^{2}$ and the triplicated waveform shape of $S^{2}$. At $39^{\circ}$ the large single pulse produced by the coherent crossing of the $\mathrm{AB}$ and $\mathrm{CD}$ branches is well replicated in the synthetics. The pulse broadening produced in four records at $39.6^{\circ}-40.5^{\circ}$ and the shoulder which develops as the phases move apart is very close to that observed in the data. Coherency in branch move out is also observed at $44^{\circ}$ and is again well replicated by the synthetics.

[28] Despite higher noise in these data, the subtleties of the triplication indicate little inferable lateral variation in the discontinuity depths. The constructive interference of the triplication structure is matched by the synthetics computed from the same model preferred for the $S^{3}$ data. The pulse broadening as the $\mathrm{AB}$ and $\mathrm{CD}$ branches of the $405-\mathrm{km}$ triplication move apart is well replicated, as are the general relative amplitudes of $S$ and $S^{2}$, which together indicate that the model reproduces the phase crossovers observed in the data. Notable misfits include the late synthetic $S^{2}$ packet at MHC $\left(44.5^{\circ}\right)$ and BKS $\left(45.3^{\circ}\right)$ and the early arrival at WDC $\left(48^{\circ}\right)$. However, while synthetic $S^{2}$ alternates between early and late across the record section, there is no systematic change in either $S^{2}$ timing or waveform shape as their ray paths swing away from the East Pacific Rise.

[29] Any such systematic, regional differences between the transition zone here and that sampled by $S^{3}$ farther from the East Pacific Rise would alter the style of interference, causing both to have a noticeable waveform distortion through branch time shifts. Figure 13 demonstrates this waveform sensitivity to $7.5-\mathrm{km}$ radial changes in both the 405- and 660-km discontinuity depths and quantifies the minimum lateral variation needed to change the interference we observe in the data. Figure 13 (middle) shows synthetics from the model in Figure 5, with the discontinuities placed at 405 and $660 \mathrm{~km}$ depth, while those in Figure 13 (right) and Figure 13 (left) have the transition zone thinned and thickened by $15 \mathrm{~km}$. For a thicker version the synthetic $S^{2}$ packet is late between $38.8^{\circ}$ and $40.5^{\circ}$, while in Figure 13 (right) the packet is early over nearly the entire profile. Also, the crossover interference is less well matched on either perturbation to the $255-\mathrm{km}$ transition zone thickness. Within the resolution of these fits the TZ structure here is identical to that which fits the $S^{3}$ phases propagating on average $500 \mathrm{~km}$ farther from the ridge axis. 


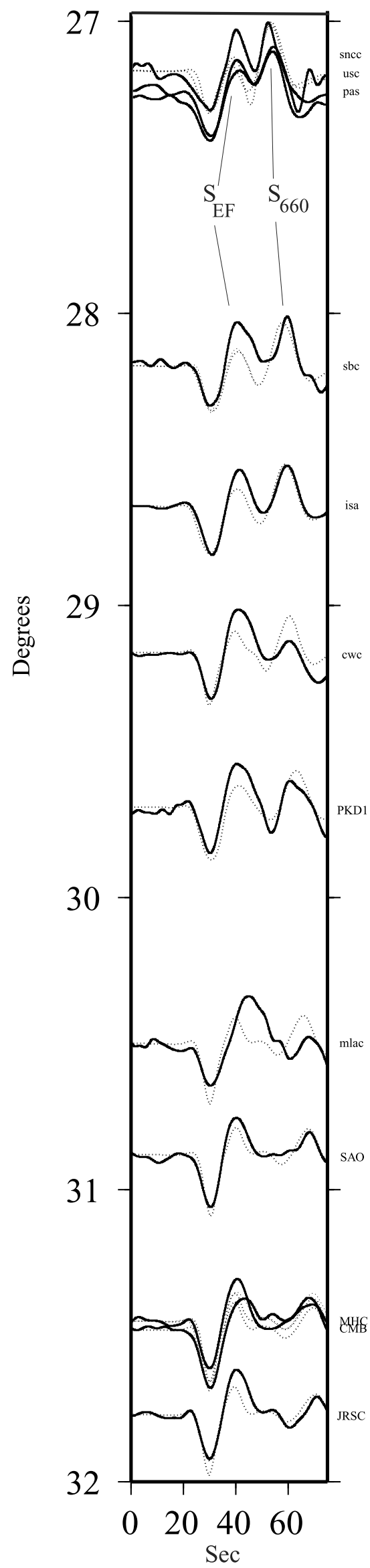

\subsection{Triplicated $S$}

[30] The D branch of the $S 660-\mathrm{km}$ triplication (box C, Figure 4) is clearly observed following lower mantle turning $\mathrm{F}$ branch at ranges $27^{\circ}-32^{\circ}$. Synthetics for these data, computed with the same model as the $S^{2}$ and $S^{3}$ data, are shown in Figure 14 . Beyond $27^{\circ}$, the timing and relative amplitudes of the lower mantle turning $\mathrm{F}$ branch and the fading $660-\mathrm{km}$ discontinuity branch fit relatively well; the scatter between waveforms is most likely due to local structure, in that there are no obvious trends in the misfit through the data. The decay rate of the $\mathrm{D}$ branch is appropriate in that it overestimates and underestimates the amplitude on adjacent traces, indicating that in an average sense the decay is well modeled. The data are more heavily attenuated at some stations known to be complex (e.g., Mammoth Lakes, MLAC) and are included for completeness.

\section{Discussion}

[31] With the exception of the lithosphere, the fact that a single mantle shear structure fits the EPR $S H$ data propagating north into California indicates a very high degree of homgeneity in the upper mantle and transition zone. Coherence of the triplication branches across any particular one of the record sections shown in Figure 7, 12 , or 14 is fragile and easily destroyed by lateral variation along the discontinuities with magnitudes routinely observed beneath continents [Dueker and Sheehan, 1997; Burdick and Helmberger, 1978], in most subduction zones globally [Niu et al., 2000; Tajima and Grand, 1995, 1998; Roth and Wiens, 1999; Clarke, 1995; Li et al., 2000; Krishna and Kaila, 1995; Shito and Shibutani, 2001; Kato et al., 2001], or near active rifts like East Africa [Owens et al., 2000; Nyblade et al., 2000; Ritsema et al., 1998]. The coherence that we observe would be lost with even a single lower mantle upwelling feeding any of the four proposed hot spots along the EPR [Richards et al., 1988]. For instance, numerical modeling suggests that a lower mantle plume directly feeding a ridge would produce lateral thermal gradients of the order $300^{\circ} / 500 \mathrm{~km}$ [Moore et al., 1999; Schilling, 1991; Anderson, 1989], while even normal Bénard convection, without narrow plumes, can produce thermal anomalies of $\pm 200^{\circ} \mathrm{C}$ [Niemela, 2000]. In a purely peridotite transition zone, $\alpha-\beta$ and $\gamma$-spinel to perovskite and magnesiowustite olivine Clapeyron slopes for the 405- and 660-km discontinuities of $2.5 \mathrm{MPa} / \mathrm{K}$ [Katsura and Ito, 1989] and $-3.0 \mathrm{MPa} / \mathrm{K}$ [Akaogi and Ito, 1993], respectively, indicate that a $200^{\circ} \mathrm{C}$ thermal anomaly should produce transition zone thickening of $35 \mathrm{~km}$. These estimates are largely independent of the detailed Clapeyron numbers, whose most recent estimations lie within a factor of 2 of one another $(\alpha-\beta$ ranges from $1.5 \pm 0.8 \mathrm{MPa} / \mathrm{K}$ [Akaogi et al., 1989] to $2.9 \mathrm{MPa} / \mathrm{K}$ [Chopelas, 1991],

Figure 14. (opposite) Back branch of the $S 660-\mathrm{km}$ triplication with synthetics computed from the same model as used with $S^{2}$ and $S^{3}$ (Figure 5). We see no evidence of systematic change in 660 depth or character relative to the observations farther form the ridge axis. 
while the $\gamma$-spinel to perovskite and magnesiowustite Clapeyron numbers range from $-2 \mathrm{MPa} / \mathrm{K}$ [Ito and Yamada, 1982] to -2 to $-3 \mathrm{MPa} / \mathrm{K}$ [Bina and Helffrich, 1994] to $-4 \pm-2 \mathrm{MPa} / \mathrm{K}$ [Ito et al., 1990]). Also, whether the transition zone is pyrolitic [Gaherty et al., 1999a] or piclogitic [Duffy and Anderson, 1989] represents less than a $20 \%$ variation in olivine content, also not expected to significantly impact this estimate. Such topography would be straightforward to identify with triplicated waveforms, given the resolution provided by the triplication branch fits.

[32] A wider aperture constraint on mantle homogeneity arises from the fact that neither can we infer any systematic variation in the $\mathrm{TZ}$ discontinuities between the four spatially separated earthquakes whose $\mathrm{TZ}$ sample regions are distant from one another. Perpendicular to the axis, each event's recordings together span ranges upward of $1000 \mathrm{~km}$ (20 Ma crust) from the East Pacific Rise spreading axis. Using the $10-\mathrm{km}$ resolution estimate above and Clapeyron slopes for the 405- and 660-km discontinuities of 2.5 and $-3 \mathrm{MPa} / \mathrm{K}$ yields a maximum thermal gradient across the ray paths sampled here of only $50^{\circ} \mathrm{C}$, lower than the thermal signature inferred at upper mantle depths beneath hot spots [Schilling, 1991]. Together, these observations require pervasive shear velocity homogeneity which could not exist with spreading ridges fed from the lower mantle.

[33] In addition, the fine structure of the discontinuities themselves might be expected to change across a strong thermal gradient associated with localized upwelling. The same phase equilibrium calculations indicate that the 405$\mathrm{km}$ discontinuity itself, caused by the $\alpha-\beta$ phase change in olivine, should increase in thickness by roughly $15 \mathrm{~km}$ for a temperature change of $215-245^{\circ} \mathrm{C}$ [Helffrich and Bina, 1994], while the $660-\mathrm{km}$ discontinuity should thicken by roughly the same amount. Although the 405-km discontinuity is not sufficiently well resolved here to tell, for the $660-\mathrm{km}$ discontinuity, as Figure 10 demonstrates, we would most likely observe the finite frequency effects on the triplicated waveform shape and amplitudes for any significant isobaric thermal variation with distance from the spreading ridge.

[34] Thus these three lines of evidence together indicate that transition zone topography expected from a direct lower mantle supply to the EPR does not exist. Since these phases travel nearly the entire length of the EPR, and a thickness anomaly greater than roughly $15 \mathrm{~km}$ along any leg is sufficient to noticeably alter the observed branch stability, this effectively rules out intermittent, regional-scale upwellings along the EPR axis. From this, we conclude that the transition zone beneath nearly the entire East Pacific Rise is not anomalous, shows no discernible difference from the global average (PREM [Dziewonski and Anderson, 1981]), and is therefore not dynamically related to spreading ridge material supply, inside a swath of crust younger than $20 \mathrm{MA}$.

[35] This is consistent with $S^{2}$ precursor studies but offers a wider-aperture, shorter-wavelength refinement similar in spatial sampling resolution to that achieved with converted phases. Globally, transition zone thickness is probably controlled primarily by topography along the $660-\mathrm{km}$ discontinuity due to its observed larger amplitude variation than that along the $405-\mathrm{km}$ discontinuity [Flanagan and
Shearer, 1998; Gu and Dziewonski, 1996; Shearer, 1993]. By utilizing a swath of independent, localized estimations of the discontinuity depths, the triplications are sensitive to finer-scale topographic variation invisible to longer-period $S^{2}$ precursor stacks.

[36] Short-wavelength topographic variation on the order of a few hundred kilometers wavelength would not be visible with this data set, although it would contribute to the triplication misfit in Figure 7. Such topography has been observed beneath both spreading ridges and continents in the vicinity of hot spots and should be ubiquitious if the thermal and dynamical state of the upper mantle proposed by Anderson [2000] proves correct. Shen et al. [1998] use $P$-to- $S$ conversions beneath Iceland and the Mid-Atlantic Ridge to image the underlying TZ, which they find to be 23 $\pm 9 \mathrm{~km}$ thinner that IASPEI91 [Kennett and Engdahl, 1991], although they can not discern how much each discontinuity contributes to the anomaly. Dueker and Sheehan [1997] image a step in the $405-\mathrm{km}$ discontinuity amounting to $25-$ $30 \mathrm{~km}$ radially over $200-300 \mathrm{~km}$ laterally beneath the Yellowstone hot spot track transect, while Beucler et al. [1999] find the $405-\mathrm{km}$ discontinuity to be badly fragmented in the same region, further evidence of fine-scale $(<300 \mathrm{~km})$ wavelength undulations. However, given the wide-aperture constraints provided by the triplication data used here, unless one contrives "feeder channels" from the lower mantle which spatially localize partial melt genesis and delivery to narrow pipes as yet undetected [Forsyth et al., 1998; Hung et al., 2000], the available evidences implies that only the shallowest mantle in the vicinity of the rise is actively involved in magma supply to the spreading ridge.

[37] Acknowledgments. This work was supported under National Science Foundation grants EAR-9973191 to Melbourne and EAR-972508 to Helmberger. Caltech Seismological Laboratory contribution 8746.

\section{References}

Agee, C. B., Phase transformations and seismic structure in the upper mantle and transition zone, in Ultrahigh-Pressure Mineralogy: Physics and Chemistry of the Earth's Deep Interior, Rev. Mineral., vol. 37, edited by R. J. Hemley and H. K. Mao, pp. 165-203, Mineral. Soc. of Am., Washington, D. C., 1998.

Akaogi, M., and E. Ito, Refinement of enthalpy measurement of $\mathrm{MgSiO}_{3}$ perovskite and negative pressure-temperature slopes for the perovskite forming reactions, Geophys. Res. Lett., 20, 1839-1842, 1993.

Akaogi, M., E. Ito, and A. Navrotsky, Olivine-modified spinel-spinel transitions in the system $\mathrm{Mg}_{2} \mathrm{SiO}_{4}-\mathrm{Mg}_{2} \mathrm{SiO}_{4}$ : Calorimetric measurments, thermochemical calculation, and geophysical application, J. Geophys. Res., 94, 15,671-15,685, 1989

Allen, R. M., et al., The thin hot plume beneath Iceland, Geophys. J. Int., 137, 51-63, 1999.

Anderson, D., Theory of the Earth, Blackwell Sci., Malden, Mass., 1989.

Anderson, D. L., The thermal state of the upper mantle: No role for mantle plumes, Geophys. Res. Lett., 27, 3623-3626, 2000.

Beucler, E., S. Chevrot, and J.-P. Montagner, The Snake River Plain experiment revisited: Relationships between a Farallon plate fragment and the transition zone, Geophys. Res. Lett., 26, 2673-2676, 1999.

Bina, C., and G. Helffrich, Phase transition Clapeyron slopes and transition zone seismic discontinuity topography, J. Geophys. Res., 99, 15,85315,860, 1994.

Bina, C., and B. Wood, The olivine-spinel transitions: Experimental and thermodynamic constraints and implications for the nature of the $400-\mathrm{km}$ seismic discontinuity, J. Geophys. Res., 92, 4853-4866, 1987.

Bouchon, M., A simple method to calculate Green's functions for elastic layered media, Bull. Seismol. Soc. Am., 71, 959-981, 1981.

Burdick, L., and D. Helmberger, The upper mantle $P$ velocity structure of the western United States, J. Geophys. Res., 83, 1699-1712, 1978. 
Burdick, L., and C. Salvado, Modeling body wave amplitude fluctuations using the three-dimensional slowness method, J. Geophys. Res., 91, 12,482-12,496, 1986.

Chaljub, E., and A. Tarantora, Sensitivity of $S S$ precursors to topography on the upper-mantle 660-km discontinuity, Geophys. Res. Lett., 24, $2613-$ 2616, 1997

Chevrot, S., L. Vinnik, and J.-P. Montagner, Global-scale analysis of the mantle Pds phases, J. Geophys. Res., 104, 20,203-20,219, 1999.

Chopelas, A., Thermal properties of $\mathrm{\beta}_{-} \mathrm{Mg}_{2} \mathrm{SiO}_{4}$ at mantle pressures derived from vibrational spectroscopy: Implications for the mantle at 400 km depth, J. Geophys. Res., 96, 11,817-11,829, 1991

Clarke, T. J., Close in $S c S$ and $S S c S$ reverberations from the 9 June, 1994 Bolivian earthquake, Geophys. Res. Lett., 22, 2313-2316, 1995.

Ding, X., and S. Grand, Upper mantle $Q$ structure beneath the East Pacific Rise, J. Geophys. Res., 98, 1973-1985, 1993.

Ding, X., and D. Helmberger, Modelling D" structure with broadband seismic data, Phys. Earth Planet. Inter., 101, 245-270, 1997.

Dueker, K. G., and A. F. Sheehan, Mantle discontinuity structure from midpoint stacks of converted $P$ waves to $S$ waves across the Yellowstone hot spot track, J. Geophys. Res., 102, 8313-8327, 1997.

Duffy, T. S., and D. Anderson, Seismic velocities in mantle minerals and the mineralogy of the upper mantle, J. Geophys. Res., 94, 1895-1912, 1989.

Dziewonski, A., and D. Anderson, Preliminary reference Earth model, Phys. Earth Planet. Inter., 25, 297-356, 1981.

Flanagan, M., and P. Shearer, Global mapping of topography on transition zone velocity discontinuities by stacking SS precursors, J. Geophys. Res., 103, 2673-2692, 1998

Forsyth, D., et al., Imaging the deep seismic structure beneath a mid-ocean ridge: The MELT Experiment, Science, 280, 1215-1217, 1998.

Gaherty, J., Y. Wang, T. H. Jordan, and D. J. Weidner, Testing plausible upper-mantle compositions using fine-scale models of the $410-\mathrm{km}$ discontinuity, Geophys. Res. Lett., 26, 1641-1644, 1999a.

Gaherty, J. B., M. Kato, and T. H. Jordan, Seismological structure of the upper mantle: A regional comparison of seismic layering, Phys. Earth Planet. Inter, 110, 21-41, 1999b.

Garnero, E., and D. Helmberger, Seismic detection of a thin laterally varying boundary-layer at the base of the mantle beneath the central Pacific, Geophys. Res. Lett., 23, 977-980, 1996.

Grand, S., Mantle shear structure beneath the America and surrounding oceans, J. Geophys. Res., 99, 11,591-11,621, 1994.

Grand, S., and D. Helmberger, Upper mantle shear structure of North America, Geophys. J. R. Astron. Soc., 76, 399-438, 1984.

$\mathrm{Gu}$, Y., and A. M. Dziewonski, Global topography of upper mantle discontinuities from $S S$ precursors, Eos Trans. $A G U, 77(46)$, Fall Meet. Suppl., F472, 1996.

Helffrich, G., and C. Bina, Frequency dependence of the visibility and depths of mantle seismic discontinuities, Geophys. Res. Lett., 21, 2613-2616, 1994.

Helmberger, D., G. Engen, and S. Grand, Upper-mantle cross-section from California to Greenland, J. Geophys., 58, 92-100, 1985.

Hung, S. H., D. W. Forsyth, and D. R. Toomey, Can a narrow, melt-rich, low-velocity zone of mantle upwelling be hidden beneath the East Pacific Rise? Limits from waveform modeling and the MELT Experiment, J. Geophys. Res., 105, 7945-7960, 2000.

Ito, E., and H. Yamada, Stability Relations of Silicate Spinels, Ilmenites and Perovskites, pp. 405-419, Cent. for Acad. Publ., Tokyo, 1982.

Ito, E., M. Akaogi, L. Topor, and A. Navrotsky, Negative pressure-temperature slopes for reactions forming $\mathrm{MgSiO}_{3}$ perovskite from calorimetry, Science, 259, 1308-1311, 1993.

Kato, M., M. Misawa, and H. Kawakatsu, Small subsidence of the 660-km discontinuity beneath Japan probed by $S c S$ reverberations, Geophys. Res. Lett., 28, 447-450, 2001

Katsura, T., and E. Ito, The system $\mathrm{Mg}_{2} \mathrm{SiO}_{4}-\mathrm{Fe}_{2} \mathrm{SiO}_{4}$ at high pressures and temperatues: Precise determination of stabilities of olivine, modified spinel, and spinel, J. Geophys. Res., 94, 15,663-15,670, 1989.

Kaula, W. M., Minimal upper mantle temperature variations consistent with observed heat flow and plate velocities, J. Geophys. Res., 88, 10,32310,332, 1983.

Kennett, B., and E. Engdahl, Travel times for global earthquake location and phase identification, J. Geophys. Int., 106, 429-465, 1991.

Krishna, V. G., and K. L. Kaila, $P$ velocity models of the mantle transition zone beneath Pacific margins, Phys. Earth Planet. Inter., 89, 247-269, 1995.
Lee, D., and S. Grand, Depth of the upper mantle discontinuities beneath the East Pacific Rise, Geophys. Res. Lett., 23, 3369-3372, 1996.

Li, X., S. V. Sobolev, R. Kind, X. Yuan, and C. Estabrook, A detailed receiver function image of the upper mantle discontinuities in the Japan subduction zone, Earth Planet. Sci. Lett., 183, 527-541, 2000.

Melbourne, T., and D. Helmberger, Mantle control of plate boundary deformation, Geophys. Res. Lett., 28, 4003-4006, 2001.

Moore, W. B., G. Schubert, and P. Tackley, The role of rheology in lithospheric thinning by mantle plumes, Geophys. Res. Lett., 26, 1073-1076, 1999.

Neele, F., H. de Regt, and J. VanDecar, Gross errors in upper-mantle discontinuity topography from underside reflection data, Geophys. J. Int., 129, 194-204, 1997.

Niemela, J. J., Turbulent convection at very high Rayleigh numbers, Nature, 404, 837-840, 2000

Niu, F., H. Inoue, D. Suetsugu, and K. Kanjo, Seismic evidence for a thinner mantle transition zone beneath the South Pacific Superswell, Geophys. Res. Lett., 27, 1981-1984, 2000.

Nyblade, A. A., T. J. Owens, H. Gurrola, J. Ritsema, and C. A. Langston, Seismic evidence for a deep upper mantle thermal anomaly beneath East Africa, Geology, 28, 599-602, 2000.

Owens, T. J., A. A. Nyblade, H. Gurrola, and C. A. Langston, Mantle transition zone structure beneath Tanzania, East Africa, Geophys. Res. Lett., 27, 827-830, 2000

Revenaugh, J., and T. Jordan, Mantle Layering from $S c S$ reverberations, 2,The transition zone, J. Geophys. Res., 96, 19,763-19,780, 1991a.

Revenaugh, J., and T. Jordan, Mantle layering from $S c S$ reverberations, 1, Waveform inversion of zeroth-order reverberations, J. Geophys. Res., 96 , 19,749-19,762, 1991b

Richards, M. A., B. H. Hager, and N. H. Sleep, Dynamically supported geoid highs over hot spots: Observation and theory, J. Geophys. Res., 93, $7690-7708,1988$

Ritsema, J., and H. V. Heijst, Seismic imaging of structural heterogeneity in Earth's mantle: Evidence for large-scale mantle flow, Sci. Progress, 83, 243-259, 1999

Ritsema, J., A. A. Nyblade, T. J. Owens, C. A. Langston, and J. C. VanDecar, Upper mantle seismic velocity structure beneath Tanzania, East Africa: Implications for the stability of cratonic lithosphere, J. Geophys. Res., 103, 21,201-21,213, 1998.

Roth, E. G., and D. A. Wiens, Depression of the $660 \mathrm{~km}$ discontinuity beneath the Tonga slab determined from near-vertical $S c S$ reverberations, Geophys. Res. Lett., 26, 1223-1226, 1999.

Saikia, C. K., Modified frequency/wavenumber algorithm for regional seismograms using Filon's quadrature-Modeling of $\mathrm{Lg}$ waves in eastern North America, Geophys. J. Int., 118, 142-158, 1994

Schilling, J. G., Fluxes and excess temperatures of mantle plumes inferred from their interaction with migrating midocean ridges, Nature, 352, $397-$ 403, 1991.

Shearer, P., Global mapping of upper mantle reflectors from long-period SS precursors, Geophys. J. Int., 115, 878-904, 1993.

Shearer, P. M., M. Flanagan, and M. Hedlin, Experiments in migration processing of $S S$ precursor data to image upper mantle discontinuity structure, J. Geophys. Res., 104, 7229-7242, 1999.

Shen, Y., A. F. Sheehan, K. G. Dueker, and H. Gilbert, Mantle discontinuity structure beneath the southern East Pacific Rise from $P$-to- $S$ converted phases, Science, 280, 1232-1234, 1998.

Shito, A., and T. Shibutani, Upper mantle transition zone structure beneath the Phillipine Sea region, Geophys. Res. Lett., 28, 871-874, 2001

Tajima, F., and S. P. Grand, Evidence of high-velocity anomalies in the transition zone associated with southern Kurile subduction zone, Geophys. Res. Lett., 22, 3139-3142, 1995.

Tajima, F., and S. P. Grand, Variation of transition zone high-velocity anomalies and depression of $660-\mathrm{km}$ discontinuity associated with subduction zones from the southern Kuriles to Izu-Bonin and Ryukyu, J. Geophys. Res., 103, 15,015-15,036, 1998.

VanderHilst, R., S. Widiyantoro, and E. Engdahl, Evidence for deep mantle circulation from global tomography, Nature, 386, 578-584, 1997.

D. V. Helmberger, Seismological Laboratory 252-21, California Institute of Technology, Pasadena, CA 91125, USA. (helm@gps.caltech.edu)

T. I. Melbourne, Department of Geological Sciences, Central Washington University, Ellensburg, WA 98926, USA. (tim@geology.cwu.edu) 